\title{
Editorial
}

\section{The Society for Neuroscience 2009 Meeting Report, Part 3}

\author{
Esther Landhuis \\ Alzheimer Research Forum
}

\section{AD AND EPILEPSY - JOINED AT THE SYNAPSE?}

One disease presents as electrical jolts that sporadically seize the brain, the other as forgetfulness and disorientation that progressively worsen. "At first pass, you'd think they are different universes," said Helen Scharfman, Nathan Kline Institute for Psychiatric Research, Orangeburg, New York, in a symposium on epilepsy and Alzheimer disease (AD) at the Society for Neuroscience (SfN) annual meeting held 17-21 October 2009 in Chicago. In the past two years, however, a closer look at these two conditions has revealed some fundamental similarities. "In both diseases, neuronal activity has gone awry in timing and synchronization," Scharfman told the assembly of epilepsy and $\mathrm{AD}$ researchers. The symposium's four presentations, as well as several posters on the topic, gave attendees plenty to chew on - highlighting links in electrophysiology, epidemiology, and animal models of the two diseases. "We believe there is some compelling clinical and experimental evidence suggesting that there could be an overlap between epilepsy and dementia, and that there could be a fruitful ground for collaboration for investigators in these areas," said symposium organizer Lennart Mucke of the Gladstone Institute of Neurological Disease in San Francisco, California.

Mucke and colleagues provided the spark for this interface when they teamed up with epileptologist Jeffrey Noebels of Baylor College of Medicine in Houston, Texas, to reveal epileptiform activity in an $\mathrm{AD}$ mouse model [1]. These abnormal discharges escape casual observation but readily showed up in electroencephalography (EEG) recordings done on freely moving J20 mice. "This confirmed our suspicion that, against what people expected, amyloid- $\beta(\mathrm{A} \beta)$ wasn't shutting the network down," Mucke told the SfN audience. Instead, $\mathrm{A} \beta$ was inducing peaks of overexcitation, which then trigger suppressive mechanisms, he suggested. "The system flips and flops between these states, resulting in an imbalance between overexcitation and inhibitory pathways in memory centers that we predict are key components of AD pathophysiology," Mucke said.

His laboratory then asked whether this network instability affects adult neurogenesis. Using retrovirus to label newborn neurons in the dentate gyrus of J20 mice, the researchers followed the cells' morphological and functional development from birth. The newborn granule cells seemed to develop on a fast track in the early stages, but later their maturation slowed down as compared to wild-type granule cells, Mucke reported. His team was able to restore normal neurogenesis by either blocking GABAergic signaling early on or inhibiting calcineurin at later stages [2].

In addition to demonstrating that the network instability in $\mathrm{AD}$ mice has functional consequences, Mucke noted that his laboratory has found sodium channel abnormalities in J20 inhibitory interneurons. These findings, currently under review, could help reconcile the conundrum that $\mathrm{A} \beta$, which is thought to dampen synaptic activity [3], can in fact make networks hyperactive. If inhibitory interneurons are impaired, the end result is network disinhibition, Mucke told the Alzheimer 
Research Forum (ARF) in a post-symposium interview. Work published earlier this year by Dennis Selkoe, Brigham and Women's Hospital, Boston, and colleagues suggests that $\mathrm{A} \beta$-induced neuronal overstimulation can disrupt uptake of extracellular glutamate, making neurons more prone to long-term depression [4].

A recent in vivo calcium imaging study led by Arthur Konnerth at Technical University Munich in Germany also lent credence to the notion that $\mathrm{A} \beta$ can make some neurons hyperactive [5]. In that analysis, researchers imaged cortical neurons from A $\beta$ PP $23 x P S 45$ mice and showed that while a third of the neurons were less active, about a fifth of them actually became more active.

At SfN, Konnerth presented new data from his laboratory showing that these changes in activity status seem to have functional consequences. His team analyzed neurons from the primary visual cortex of wildtype and A $\beta$ PP23xPS45 mice. They chose the visual system because the relationship between physical input (i.e., shape and orientations of images) and how the neurons typically respond to it is well described. Plus, the researchers had found amyloid plaques and impaired spontaneous neuronal activity in the mice's visual cortex in their earlier study. In the new analysis, some cells in the $\mathrm{A} \beta \mathrm{PP} 23 \mathrm{xPS} 45$ visual cortex were hypoactive and some were hyperactive, as expected. But more than that, the silent neurons in the AD mice showed no response to sensory stimuli. This was in contrast to wild-type mice, where a proportion of the silent cells were still responsive. More serious problems showed up in the $\mathrm{A} \beta \mathrm{PP} 23 x \mathrm{PS} 45$ hyperactive neurons. These cells essentially lost their ability to respond precisely to specific orientations, compared with hyperactive cells in the wild-type visual cortex, Konnerth reported.

The Mucke laboratory presented several SfN posters with mechanistic data on the relationship between synaptic dysfunction, network hyperexcitability, and behavioral deficits. Julie Harris and colleagues tried to get a handle on where $\mathrm{A} \beta$ first acts within the entorhinal-hippocampal network to wreak havoc on networks and behavior. To that end, the scientists analyzed transgenic mice expressing human mutant $\mathrm{A} \beta \mathrm{PP}$ primarily in layer $2 / 3$ pyramidal cells of the medial entorhinal cortex. These neurons signal to granule cells of the dentate gyrus, which had no detectable A $\beta$ PP expression. By the time they were six months old, the transgenic mice had molecular changes in the dentate gyrus, as well as defects in several behavioral assays, but with still hardly any $\mathrm{A} \beta$ deposition in the dentate gyrus. From these findings, they determined that $\mathrm{A} \beta$ acts trans-synaptically to induce molecular and functional impairments. In a separate poster, Jorge Palop and colleagues showed that exacerbating $\mathrm{A} \beta$-induced epileptiform activity in $\mathrm{J} 20$ mice further intensified the remodeling of hippocampal circuits and other molecular abnormalities they had characterized in their previous study [1]. The data suggest to the authors that these changes are indeed a downstream consequence of the neuronal overexcitability.

Scientists in Finland have recently extended the observations of hyperactivity to another AD transgenic line, PS-A $\beta$ PP [6]. In an SfN poster, researchers at Pfizer Global Research and Development, Princeton, New Jersey, report epileptiform activity in that same strain as well as another, $\operatorname{Tg} 2576$. Steve Leiser who has since moved to AstraZeneca in Wilmington, Delaware - and colleagues found hyperexcitability in PS-A $\beta$ PP mice at 21, 34, and 47 weeks, and in $\operatorname{Tg} 2576$ mice at 27 and 34 weeks. Like the J20 mice, the Tg2576 and PS-A $\beta$ PP animals showed freezing behavior but had no tremors, convulsions, or other visible signs of overt seizures. Both strains showed epileptiform activity only after $\mathrm{A} \beta$ deposition had begun but before measurable cognitive decline, Leiser wrote in an e-mail to ARF. The EEG recordings also revealed a shift from delta (slow-wave) toward theta activity in the transgenic mice, suggesting their brains are in a hyperexcited state. Leiser noted that this pattern parallels that of $\mathrm{AD}$ patients, who show an increase in theta power early in the disease, and later shift back to a high delta state. "These EEG features could indicate a hyperexcitable state predictive of seizures, and might serve as a biomarker for preclinical AD," he wrote.

\section{AD AND EPILEPSY - LESSONS FROM THE CLINIC, ANIMALS}

$\mathrm{SfN}$ featured a rare convergence of epilepsy and AD researchers at a symposium focused on shared features of these two disorders. There is accumulating animal data for such a connection: At least three strains of AD transgenic mice show epileptiform activity on EEG recordings, and the data hint that the EEG changes could be a signature for impending cognitive decline. There is also growing suspicion that the same may be true for AD patients. In a slide talk, Jeffrey Noebels, an epilepsy researcher at Baylor College of Medicine in Houston, Texas, reviewed clinical and pathological evidence for overlap between $\mathrm{AD}$ and temporal lobe epilepsy (TLE). He proposed that seizures may be a 
common feature of AD that escapes detection by conventional EEG. Physicians spend a lot of time figuring out whether patients have AD or TLE, Noebels said, noting, "It's actually possible to have both."

Epidemiological data points in this direction. Epilepsy is generally a childhood disease but seems to occur more frequently in seniors with dementia [7]. More than half of the rare early-onset $\mathrm{AD}$ patients with $\mathrm{A} \beta \mathrm{PP}$ duplications have seizures [8], and for those with very early onset of dementia (i.e., under 40 years of age), the incidence of epilepsy rises to 83 percent [9].

When made to hyperventilate, people who carry an apolipoprotein E4 (ApoE4) allele, which puts them at increased AD risk, show epileptiform activity on EEG [10]. An SfN poster by Jesse Hunter, Eli Lilly and Co., Indianapolis, Indiana, and colleagues showed mouse data that support this view. The scientists analyzed E2, E3, and E4 targeted replacement mice (i.e., transgenic mice that express a given human ApoE allele in the endogenous locus) and report that old E4 females developed seizures whereas E2 and E3 mice did not.

Meanwhile, the overall proportion of people with $\mathrm{AD}$ and mild cognitive impairment (MCI) patients who have non-convulsive seizures remains unknown - in large part because probing the right brain regions is difficult. It is much easier to pick up epileptiform activity in mice, where the cortex is just a millimeter thick and the hippocampus is disproportionately large, Noebels said. In the human brain, surface EEG readily misses abnormal activity in the temporal lobe, the main site of early AD pathology, because this brain structure is small and deep - buried within a comparatively thick cortex. Noebels described a case where nothing showed up on a surface EEG recording, but implanted depth electrodes revealed a full-blown seizure. Mindful of these challenges, scientists at the University of California, San Francisco, launched a study earlier this year to determine the incidence of epileptiform activity in dementia patients by doing 36-hour EEG and magnetoencephalography (MEG) on study volunteers with AD and MCI, said symposium chair Lennart Mucke of the Gladstone Institute of Neurological Disease in San Francisco, California.

The notion of an interface between AD and TLE appears to be gaining traction among AD researchers. "People I talked with were fascinated by the overlap, which seems wider than is realized by the experimental and clinical evidence that has accumulated in a fairly short period of time," Mucke told ARF. Steve Barger of the University of Arkansas, Little Rock, said the overlap with TLE might explain the vacillating clinical be- havior of some AD patients, who can seem completely disoriented for a time and then snap back into an almost-normal state. "Maybe you don't really get cognitive deficits until you get something that approaches epileptiform activity," he said.

Helen Scharfman of the Nathan Kline Institute for Psychiatric Research, Orangeburg, New York, proposed several potential shared mechanisms between AD and TLE. The first was inflammation. Clinical data suggest that infection is a risk factor for TLE, and animal studies have shown that cyclooxygenase- 2 inhibitors can help restore long-term potentiation in an AD model [11] and decrease seizures in a TLE model [12]. Another common mechanism could be neurogenesis, Scharfman said. In rodents, the dentate gyrus makes new neurons after seizures [13], and the neurogenesis seems to contribute to hippocampal network reorganization [14]. Neurogenesis is also increased early - by three to four months of age - in Tg2576 AD mice [15].

Some TLE models might actually be unique tools for studying AD because they model features that amyloidosis models do not capture, Scharfman suggested. For example, the loss of basal forebrain cholinergic neurons is a common feature in AD patients, yet is hardly detectable in mouse models based on $\mathrm{A} \beta \mathrm{PP}$ mutations and overexpression. However, cholinergic deficits do appear in the kindling model of TLE. (Kindling refers to repeated stimulation that leaves neurons oversensitized and prone to seizures). The kindling model also shares a number of common dentate gyrus features with the $\mathrm{A} / \beta \mathrm{PP} / \mathrm{PS} 1$ mouse, including reduced dentate hilar cells, interneuron loss, survival of granule cells, mossy fiber sprouting, and increased expression of neuropeptide $\mathrm{Y}$.

The experimental and clinical support for an ADTLE overlap begs the obvious question of whether antiepileptic drugs can stem the network dysfunction that presumably leads to dementia. So far, this has not been the case. When Mucke and colleagues treated J20 mice with the anti-epileptic drug phenytoin, a sodium channel blocker, the animals had even more seizure activity. The findings were perplexing, he said, but perhaps not so unreasonable given that some epilepsy patients with loss-of-function mutations in voltage-gated sodium channels also respond poorly to phenytoin. That observation led his team to look for sodium channel abnormalities in the cortex of their J20 mice.

Thus far, AD patients treated with epilepsy drugs have not fared any better. Phenytoin (sold under the trade name Dilantin) is often given to stop seizures 
in $\mathrm{AD}$, but it tends to worsen cognition, Mucke told ARF. And a recent Phase III trial of the anticonvulsant valproate failed to improve neuropsychiatric symptoms in AD patients. Principal investigator Pierre Tariot of Banner Alzheimer's Institute, Phoenix, Arizona, presented the trial results at this year's International Conference on Alzheimer's Disease (ICAD) in Vienna.

Much work remains to contrast and compare the mechanisms at work in epilepsy and network dysfunction in AD, Mucke said. "But at least people felt there was good reason to pay attention to that interface."

\section{THE VAMPIRE PRINCIPLE - YOUNG BLOOD REJUVENATES AGING BRAIN?}

Bram Stoker would have loved it. One hundred twelve years after the Irish author penned Dracula, his bone-chilling masterpiece, scientists at the SfN conference confirmed the vampire principle, whereby young blood keeps an aging organism vigorous. Of course, the qualifications that must follow such a breezy analogy are manifold. To begin with, the research involved not fair maidens and an ancient count but young and old mice, none of them evil. But in essence, scientists did report that admixing young blood to old rejuvenated the aging brain's otherwise flagging output of newly generated neurons. The scientists identified some of the molecular factors, to boot. Presented in a talk by Saul Villeda, a Ph.D. student in the laboratory of Tony Wyss-Coray at Stanford University, the research features a combination of the laboratory's parabiosis (i.e., blood-mixing) experiments with proteomics and follow-up studies in vitro and in vivo. The data presented to date are about aging, not AD, but the scientists are actively studying what their findings could mean for this neurodegenerative disease.

Aging remains the biggest risk factor for $\mathrm{AD}$, and it can be viewed as a shift over time in the body's balance of regenerative capacity versus degeneration, Villeda said. The immune system, in particular, changes with aging. Indeed, many of the signaling proteins active in aging, in stressed neurons, and in activated glial cells are proteins that were originally named by immunologists but function in the brain, as well. "It has been shown that as we age, and in $\mathrm{AD}$, inflammatory proteins in blood correlate with degenerative brain disease in certain ways. The drive behind my work is that I am interested particularly in the regenerative aspect of blood-derived factors, and I view neural stem cells as a readout of that," Villeda said.
The importance of adult neurogenesis is not fully established, but scientists increasingly believe the new neurons are functionally relevant to olfaction and perhaps learning [16]. Adult neurogenesis in young and old animals also responds to external stimuli such as exercise, which increases blood supply to the brain and benefits learning and memory.

Wyss-Coray's group has found, as have published studies before, that adult neurogenesis in the hippocampal subgranular zone of mice dwindles as they age, to where it hovers near zero by the time they are two years old. To pinpoint peripheral factors that might correlate with the age-related decline in neurogenesis, the Wyss-Coray laboratory conducted a proteomics study of blood from healthy humans at different ages and then tested if the protein signature that came up in this experiment was able to predict age in a similar proteomics run in mice. (As in an earlier proteomics study $[17,18]$, the Stanford scientists restricted their comparison to proteins involved in what they call the "communicome," i.e., the several hundred secreted proteins known to be involved in signaling among cells of the immune system. This narrows by about a factor of 100 to 1,000 , respectively, the challenge of drawing biological meaning out of changes in the entire transcriptome or proteome.) This new proteomics experiment generated a short list of some 12 plasma proteins, of which eotaxin and MCP-1 looked most intriguing, Villeda said.

To take these correlative clues to a functional level, the researchers availed themselves of a technique called parabiosis, where a scientist opens the peritoneum of two mice and sutures them together. This is not vascular surgery; rather, the capillary beds of both mice fuse as their tissue heals. Jian Luo in the Wyss-Coray laboratory in this way conjoined several dozen pairs of one two-month old and one 18-month old mice. The pairs then lived as unequal Siamese twins of sorts (one small and fluffy, one large and a bit scruffy). They did that for two months while old blood mixed with young. Parabiosis is not new in science [19]. The new aspect here is the combination of young, old, and a neurogenesis readout.

When the mice were four and 20 months old, respectively, Villeda assessed several readouts in the brain. The scientists were startled to find that the young mice exposed to old blood had a drop in neurogenesis as measured by doublecortin-positive cells in the hippocampus, whereas the old mice exposed to young blood enjoyed a threefold boost in their neurogenesis. The newly differentiated neurons in these "Dracula" mice grew longer neurites, too. Also in the hippocampus, the 20- 
month-old mice were spared the increase in activated microglia that is typically seen in aging mice, whereas the four-month-old mice did show that increase.

Next, the scientists probed whether the candidate factors eotaxin and MCP-1 might play a role in this phenomenon. The concentration of both proteins went up in the brain of young mice connected to old blood, as indeed it does in normally aging mice. These proteins also increase with age in human plasma and cerebrospinal fluid, Villeda noted. When tested in vitro, eotaxin slowed stem cell proliferation and neurosphere growth. Similar results came out of in vivo imaging using a transgenic mouse that expresses the luciferase reporter gene under the control of the doublecortin promoter. In this model, differentiation of neural progenitor cells lights up in living animals placed under a bioluminescence camera [20]. This readout dimmed within days after these mice were injected with eotaxin. The mice were made in the laboratory of Ludwig Aigner of Paracelsus Medical University in Salzburg, Austria, a coauthor of this study.

"We think these proteins are bad guys in aging," Villeda said. Eotaxin has its own literature, though hardly any published work in brain $[21,22]$. At the conference, the Stanford scientists presented no experimental data on MCP-1, which is receiving growing attention in AD research $[23,24]$. In an interview, Villeda noted that experiments with MCP-1 are ongoing, as well as studies with AD models and repeat parabiosis experiments in other mouse strains.

Villeda emphasized that he believes eotaxin and other such signals enter the brain from the periphery. In fact, the neurogenic niche - a specialized microenvironment in the subventricular zone and the dentate gyrus appears particularly well positioned to receive molecular cues from the blood. These niches occupy a physical space in which the blood-brain barrier appears to be altered. Several recent studies on the microanatomy of the neurogenic niche have concluded that not only do neural stem cells in the niche make intimate contact with the vascular surface, but they also react to soluble factors released from vascular endothelial cells. Stem cells in vivo were reported to proliferate right next to blood vessels. By comparison, the rest of the brain is more solidly walled off from blood by the classic blood-brain barrier comprising pericytes and astrocytes endfeet, both of which cover the outside of the vascular endothelium $[25,26]$.

Besides neurogenesis, what else did the scientists observe about the parabiotic mice? The laboratory did not conduct a comprehensive examination, but Villeda did notice one curious change. By the end of the bloodsharing period, the old mice, which had gone into it with quite a bit of gray hair, had regrown the dark fur of the C57 black 6 strain used in the experiment. They also had lower mortality than their naturally aging fellow mice and looked a little less - well - old. "There is a rejuvenating ability in young blood onto an aged brain," said Villeda. Then he quipped, "Maybe Dracula was right: Suck young blood and live forever."

\section{NFATs, CALCINEURIN - MEDIATORS OF AD, PARKINSON DISEASE PATHOGENESIS?}

At the SfN conference, several posters beefed up the concept that signaling via calcineurin and nuclear factors of activated T cells (NFATs) may play a central role in neurodegenerative disease pathogenesis. One study puts forth calcineurin activation as a critical step linking soluble $\mathrm{A} \beta$ to downstream spine morphological changes in neurons. Other analyses reveal elevated levels of activated calcineurin in people with MCI, suggesting that this pathway starts to malfunction early in the disease course. And work from a third research group indicates that calcineurin may function similarly in Parkinson disease, mediating the neurotoxic effects of $\alpha$-synuclein oligomers.

Using multiphoton imaging, Brad Hyman and colleagues at Massachusetts General Hospital, Charlestown, have reported dramatic changes in dendrites and dendritic spines in the vicinity of amyloid plaques in Tg2576 AD transgenic mice [27]. Paul Greengard's laboratory at Rockefeller University, New York, showed that interfering with extracellular signalregulated kinase (ERK) or calcineurin pathways was sufficient to block $\mathrm{A} \beta$-induced spine changes in vitro [28]. And more recent work led by Massachusetts General colleague Brian Bacskai demonstrated that $\mathrm{A} \beta$ plaques have even more far-reaching effects - namely, chronic elevations of resting calcium levels in surrounding astrocytes that spread as calcium waves across large distances [29]. Taken together, these findings "led to the plausible hypothesis that one of the things calcium does is activate calcineurin," Hyman told ARF. "That would be a nice way to link Greengard's observations in vitro with our observations in vivo."

In their SfN poster, first author Haiyan Wu and colleagues showed that $\mathrm{A} \beta$ exposure led to dendritic spine changes, as well as activation and nuclear translocation of NFATc4, in cultured cortical neurons. They were able to block all these effects using calcineurin or NFAT 
inhibitors. "That suggests that calcineurin activation was a critical signaling mechanism that converts soluble A $\beta$ to neuronal abnormality," Hyman said. Furthermore, his team was able to phenocopy the $\mathrm{A} \beta$-induced changes in wild-type neurons by transfecting them with a constitutively active form of calcineurin, showing that calcineurin is not only necessary but sufficient to mediate the $\mathrm{A} \beta$ effects.

Hyman and colleagues have some evidence to suggest these findings are relevant to AD. They found accumulation of NFATc4 and an active form of calcineurin in nuclear extracts from $\mathrm{AD}$ compared to control brain tissue.

This supports new data from Chris Norris's laboratory at the University of Kentucky in Lexington. In a study published last month, first author Hafiz Abdul and colleagues found higher amounts of several activated NFATs in nuclear fractions of postmortem brain tissue from MCI and AD patients, relative to healthy seniors [30].

At SfN, Abdul and colleagues presented a poster showing a corresponding increase in activation of calcineurin - the phosphatase that regulates NFAT activity - in the same MCI and AD samples. Previous work had demonstrated increases in calpain-mediated proteolysis and activation of calcineurin in severe AD [31], and the new data from Norris's group suggest that these abnormalities begin in earlier stages of disease. Specifically, Abdul and colleagues found that MCI cytosolic fractions had higher levels of calpain- 1 and the $45 \mathrm{kDa}$ activated calcineurin-A $\alpha$ fragment. Treatment with oligomeric $\mathrm{A} \beta$ was able to induce proteolysis of calcineurin to the $45 \mathrm{kDa}$ fragment in mixed hippocampal cultures, and the calpain inhibitor calpeptin tempered this activity.

On another poster from the Norris lab, Jennifer Furman and colleagues reported looking at production of inflammatory cytokines, the downstream effect of NFAT-mediated signal transduction. They found that GM-CSF, TNF $\alpha$, and IL- $1 \beta$ are upregulated in AD, and to some extent in brain samples from MCI and milder "preclinical" patients, too. (Patients were classified as control, MCI, or preclinical based on pathology and cognitive status as determined by the MiniMental State Examination (MMSE). The control and preclinical groups had MMSE scores of 28-29, and MCI participants had scores around 24.) Levels of the three upregulated cytokines seemed to correlate with nuclear accumulation of NFAT1, but not NFATs 2 or 3 . As reported on the poster, these findings suggest that "at least some components of neuroinflammation are increased in the very early stages of AD and are due, in part, to elevated NFAT1 activation."

Last but not least, work by Giulio Taglialatela and colleagues at University of Texas Medical Branch, Galveston, suggests that the calcineurin/NFAT pathway may play a central role in Parkinson disease, too. Earlier, his group showed that oligomeric $\mathrm{A} \beta$ induces calcineurin activity and triggers downstream neurotoxic events in $\mathrm{Tg} 2576$ neurons [32]. In their SfN poster, Taglialatela and colleagues show that oligomers of $\alpha$ synuclein that are structurally similar to $\mathrm{A} \beta$ oligomers mediate similar calcineurin-dependent events in human neuroblastoma cells and mice. Furthermore, they report increased calcineurin activity in the brains of transgenic mice overexpressing mutant $\alpha$-synuclein and in brain tissue from people with dementia with Lewy bodies, a dementia spectrum disorder that combines elements of $\mathrm{AD}$ and Parkinson disease.

\section{REFERENCES}

[1] Palop JJ, Chin J, Roberson ED, Wang J, Thwin MT, Bien-Ly N, Yoo J, Ho KO, Yu GQ, Kreitzer A, Finkbeiner S, Noebels JL, Mucke L (2007) Aberrant excitatory neuronal activity and compensatory remodeling of inhibitory hippocampal circuits in mouse models of Alzheimer's disease. Neuron 55, 697-711.

[2] Sun B, Halabisky B, Zhou Y, Palop JJ, Yu G, Mucke L, Gan L (2009) Imbalance between GABAergic and glutamatergic transmission impairs adult neurogenesis in an animal model of Alzheimer's disease. Cell Stem Cell 5, 624-633.

[3] Kamenetz F, Tomita T, Hsieh H, Seabrook G, Borchelt D, Iwatsubo T, Sisodia S, Malinow R (2003) APP processing and synaptic function. Neuron 37, 925-937.

[4] Li S, Hong S, Shepardson NE, Walsh DM, Shankar GM, Selkoe D (2009) Soluble oligomers of amyloid Beta protein facilitate hippocampal long-term depression by disrupting neuronal glutamate uptake. Neuron 62, 788-801.

[5] Busche MA, Eichhoff G, Adelsberger H, Abramowski D, Wiederhold KH, Haass C, Staufenbiel M, Konnerth A, Garaschuk O (2008) Clusters of hyperactive neurons near amyloid plaques in a mouse model of Alzheimer's disease. Science 321, 1686-1689.

[6] Minkeviciene R, Rheims S, Dobszay MB, Zilberter M, Hartikainen J, Fülöp L, Penke B, Zilberter Y, Harkany T, Pitkänen A, Tanila H (2009) Amyloid beta-induced neuronal hyperexcitability triggers progressive epilepsy. J Neurosci 29, 34533462.

[7] Cloyd J, Hauser W, Towne A, Ramsay R, Mattson R, Gilliam F, Walczak T (2006) Epidemiological and medical aspects of epilepsy in the elderly. Epilepsy Res 68 (Suppl 1), S39-48.

[8] Cabrejo L, Guyant-Maréchal L, Laquerrière A, Vercelletto M, De la Fournière F, Thomas-Antérion C, Verny C, Letournel F, Pasquier F, Vital A, Checler F, Frebourg T, Campion D, Hannequin D. Phenotype associated with APP duplication in five families. Brain 129 (Pt 11), 2966-2976.

[9] Snider BJ, Norton J, Coats MA, Chakraverty S, Hou CE, Jervis R, Lendon CL, Goate AM, McKeel DW, Morris JC (2005) Novel presenilin 1 mutation $(\mathrm{S} 170 \mathrm{~F})$ causing Alzheimer dis- 
ease with Lewy bodies in the third decade of life. Arch Neurol 62, 1821-1830.

[10] Ponomareva NV, Korovaitseva GI, Rogaev EI (2008) EEG alterations in non-demented individuals related to apolipoprotein E genotype and to risk of Alzheimer disease. Neurobiol Aging 29, 819-827.

[11] Kotilinek LA, Westerman MA, Wang Q, Panizzon K, Lim GP, Simonyi A, Lesne S, Falinska A, Younkin LH, Younkin SG, Rowan M, Cleary J, Wallis RA, Sun GY, Cole G, Frautschy S, Anwyl R, Ashe KH (2008) Cyclooxygenase-2 inhibition improves amyloid-beta-mediated suppression of memory and synaptic plasticity. Brain 131 (Pt 3), 651-664.

[12] Jung KH, Chu K, Lee ST, Kim J, Sinn DI, Kim JM, Park DK, Lee JJ, Kim SU, Kim M, Lee SK, Roh JK (2006) Cyclooxygenase- 2 inhibitor, celecoxib, inhibits the altered hippocampal neurogenesis with attenuation of spontaneous recurrent seizures following pilocarpine-induced status epilepticus. Neurobiol Dis 23, 237-246.

[13] Bengzon J, Kokaia Z, Elmér E, Nanobashvili A, Kokaia M, Lindvall O (1997) Apoptosis and proliferation of dentate gyrus neurons after single and intermittent limbic seizures. Proc Natl Acad Sci U S A 94, 10432-10437.

[14] Parent JM, Yu TW, Leibowitz RT, Geschwind DH, Sloviter RS, Lowenstein DH (1997) Dentate granule cell neurogenesis is increased by seizures and contributes to aberrant network reorganization in the adult rat hippocampus. J Neurosci 17 3727-3738.

[15] López-Toledano MA, Shelanski ML (2007) Increased neurogenesis in young transgenic mice overexpressing human APP(Sw, Ind). J Alzheimers Dis 12, 229-240.

[16] Kokovay E, Shen Q, Temple S (2008) The incredible elastic brain: how neural stem cells expand our minds. Neuron 60 , 420-429.

[17] Ray S, Britschgi M, Herbert C, Takeda-Uchimura Y, Boxer A, Blennow K, Friedman LF, Galasko DR, Jutel M, Karydas A, Kaye JA, Leszek J, Miller BL, Minthon L, Quinn JF, Rabinovici GD, Robinson WH, Sabbagh MN, So YT, Sparks DL, Tabaton M, Tinklenberg J, Yesavage JA, Tibshirani R, Wyss-Coray $\mathrm{T}$ (2007) Classification and prediction of clinical Alzheimer's diagnosis based on plasma signaling proteins. Nat Med $\mathbf{1 3}$ 1359-1362.

[18] Britschgi M, Wyss-Coray T (2009) Blood protein signature for the early diagnosis of Alzheimer disease. Arch Neurol 66, 161-165.

[19] Mildner A, Schmidt H, Nitsche M, Merkler D, Hanisch UK, Mack M, Heikenwalder M, Brück W, Priller J, Prinz M (2007) Microglia in the adult brain arise from Ly-6ChiCCR2+ monocytes only under defined host conditions. Nat Neurosci 10, 1544-1553.

[20] Couillard-Despres S, Finkl R, Winner B, Ploetz S, Wiedermann D, Aigner R, Bogdahn U, Winkler J, Hoehn M, Aigner L (2008) In vivo optical imaging of neurogenesis: watching new neurons in the intact brain. Mol Imaging 7, 28-34.

[21] Xia MQ, Qin SX, Wu LJ, Mackay CR, Hyman BT (1998) Immunohistochemical study of the beta-chemokine receptors CCR3 and CCR5 and their ligands in normal and Alzheimer's disease brains. Am J Pathol 153, 31-37.

[22] Choi C, Jeong JH, Jang JS, Choi K, Lee J, Kwon J, Choi KG, Lee JS, Kang SW (2008) Multiplex analysis of cytokines in the serum and cerebrospinal fluid of patients with Alzheimer's disease by color-coded bead technology. J Clin Neurol 4, 8488.

[23] Galimberti D, Schoonenboom N, Scheltens P, Fenoglio C, Bouwman F, Venturelli E, Guidi I, Blankenstein MA, Bresolin $\mathrm{N}$, Scarpini E (2006) Intrathecal chemokine synthesis in mild cognitive impairment and Alzheimer disease. Arch Neurol 63, 538-543.

[24] Galimberti D, Fenoglio C, Lovati C, Venturelli E, Guidi I, Corrà B, Scalabrini D, Clerici F, Mariani C, Bresolin N, Scarpini E (2006) Serum MCP-1 levels are increased in mild cognitive impairment and mild Alzheimer's disease. Neurobiol Aging 27, 1763-1768.

[25] Tavazoie M, Van der Veken L, Silva-Vargas V, Louissaint M, Colonna L, Zaidi B, Garcia-Verdugo JM, Doetsch F (2008) A specialized vascular niche for adult neural stem cells. Cell Stem Cell 3, 279-288.

[26] Shen Q, Wang Y, Kokovay E, Lin G, Chuang SM, Goderie SK, Roysam B, Temple S (2008) Adult SVZ stem cells lie in a vascular niche: a quantitative analysis of niche cell-cell interactions. Cell Stem Cell 3, 289-300.

[27] Spires TL, Meyer-Luehmann M, Stern EA, McLean PJ, Skoch J, Nguyen PT, Bacskai BJ, Hyman BT (2005) Dendritic spine abnormalities in amyloid precursor protein transgenic mice demonstrated by gene transfer and intravital multiphoton microscopy. J Neurosci 25, 7278-7287.

[28] Snyder EM, Nong Y, Almeida CG, Paul S, Moran T, Choi EY, Nairn AC, Salter MW, Lombroso PJ, Gouras GK, Greengard P (2005) Regulation of NMDA receptor trafficking by amyloidbeta. Nat Neurosci 8, 1051-1058.

[29] Kuchibhotla KV, Lattarulo CR, Hyman BT, Bacskai BJ (2009) Synchronous hyperactivity and intercellular calcium waves in astrocytes in Alzheimer mice. Science 323, 1211-1215.

[30] Abdul HM, Sama MA, Furman JL, Mathis DM, Beckett TL, Weidner AM, Patel ES, Baig I, Murphy MP, Levine H, Kraner SD, Norris CM (2009) Cognitive decline in Alzheimer's disease is associated with selective changes in calcineurin/NFAT signaling. J Neurosci 29, 12957-12969.

[31] Liu F, Grundke-Iqbal I, Iqbal K, Oda Y, Tomizawa K, Gong CX (2005) Truncation and activation of calcineurin A by calpain I in Alzheimer disease brain. J Biol Chem 280, 37755-37762.

[32] Reese LC, Zhang W, Dineley KT, Kayed R, Taglialatela G (2008) Selective induction of calcineurin activity and signaling by oligomeric amyloid beta. Aging Cell 7, 824-835. 